\title{
Yang Zhu’s “Guiji” Yangsheng and Its Modern Relevance
}

\author{
Yanxia Zhao \\ University of Wales Trinity Saint David
}

\begin{abstract}
Condemned by Mencius (ca.372-289 BCE) as selfishness (weiwo, 为我), Yang Zhu’s yangsheng philosophy in China is traditionally depicted as a philosophy of egoism and hedonism. In contrast, Yang Zhu (fl.ca.370-350 BCE) is described as an "early liberal or individualist” hero in the Western Discussion of Chinese Philosophy. Yang Zhu may not be a liberal or individualist hero as portrayed by the West, but surely he should not be depicted as a promoter of egoism as Mencius did. Both John Emerson and A.C. Graham are probably right when they claimed that Yang Zhu was a revolutionary thinker of his own time; and "Yang Zhu's intervention for the Chinese thinking world had provoked a metaphysical crisis which had threatened the basic assumptions of Confucianism and Mohism and set them into a new course” (A.C. Graham 1978). From my reading, Yang Zhu's influence on Chinese philosophy had been and will be even greater, although his philosophy as a whole was not practiced by Chinese society in the past due to the dominance of Confucianism. Yet as the first person who clearly emphasized nourishing of life for individuals and the first theory that rooted morality into xing (性, human nature), Yang Zhu's yangsheng philosophy had indeed through history made a huge contribution to Chinese nurturing life tradition, and had great potential in providing inspiration to modern moral thinking. Many discussions initiated or developed by Yang Zhu and his followers have influenced both Confucianism and Daoism profoundly. His idea of nourishing life was not only inherited and developed by Zhuangzi and later Daoist religion from life preservation perspective, but also by Mencius and Xunzi from moral cultivation perspective. As a doctrine that has shown more and more relevance to modern society, people can find many inspirations from Yang Zhu's answer to the following questions: What is the aim of human life? What is the right attitude toward life and death? What is human nature? What is the relationship between life nourishment and individual freedom? Why nourishing one's own life should be as important as nourishing that of others? What is the difference between humans and animals? Why living a natural life is so important for human beings? Based on materials collected from various Chinese sources directly related to Yang Zhu's school, especially the chapter entitled as "Yang Zhu" from the book of Liezi, this paper will explore essential features of Yang Zhu's yangsheng philosophy and its relevance to modern society. As “guiji” (贵己, cherishing oneself) is the core of Yang Zhu's yangsheng philosophy, discussion of this paper will focus on what Yang Zhu's "guiji” means, why Yang Zhu’s "guiji” is not “weiwo” (为我, for oneself), and how Yang Zhu’s "guiji” yangsheng is relevant to modern society.
\end{abstract}

Keywords: Yangsheng (nourishing life), ji (self), wo (oneself), xing (nature), guiji (cherishing self), weiwo (for oneself), quanxing (keep one’s nature intact), baozhen (protecting one’s genuineness)

Yanxia Zhao, Ph.D. in Philosophy, lecturer in Chinese Studies, School of Cultural Studies, Faculty of Humanities, University of Wales Trinity Saint David, UK; main research fields: Confucian Ethics, Daoist Life Philosophy, and Religion, and Daoist Self Health Care Exercise and its modern implement. Email: y.zhao@tsd.uwtsd.ac.uk. 


\section{Essential Characteristic of Yang Zhu’s “Guiji” Yangsheng}

Little is known of the historical Yang Zhu, ${ }^{1}$ or the authentic systematic source of his remaining philosophy. ${ }^{2}$ Yet Yang Zhu's yangsheng philosophy is famous due to its challenge to both Mohist and Confucian pragmatic altruism, and it's enhancement of the "guiji” principle.

Three features of Yang Zhu philosophy are pointed out by Huainanzi (淮南子) in its discussion on the challenge of Yang Zhu to Mohism, they are: “quanxing” (全性, keep ones nature intact), “baozhen” (保真, protect one’s genuineness), and “buyiwuweixing” (不以物累形, not allow oneself to become tied to material things). ${ }^{4}$ Guocheng Jiao gives a detail examination on how Yang Zhu challenged Mohist doctrines,

Against Modi's idea of sacrificing oneself to die in order to offer an equal and universal love to others, Yang Zhu insisted that one should treasure oneself; as opposed to Modi's idea of the promotion of selflessness with morality being the first principle, Yang Zhu suggested that one should avoid to tie oneself up to any external burdens; as opposed to Modi's appeal to ghosts for ensuring one's good performance in social and political services, Yang Zhu enhanced the idea of getting rid of the fears of ghosts in order to ensure one's spirit in peace and one's nature intact; as opposed to Modi's challenge on fate by believing that such a challenge would lead to an artificial effort for an external conquering, Yang Zhu enhanced a natural attitude toward life. (Guocheng Jiao 1989, 89) ${ }^{5}$

More features of Yang Zhu yangsheng philosophy were revealed from Yang Zhu's challenge to Confucianism. He was against Confucian benevolent moralism where sacrifice of one's personal interests for the benefits of family and state were at the centre of personal moral cultivation, Yang Zhu enhanced an idea of "guiji” in order to encourage everybody to take care of themselves. Yang believed that if only everybody focused merely on taking care of themselves rather than others, the whole world could be in peace:

Po-ch'eng-Tze-kao would not benefit others at the cost of one hair; he renounced his state and retired to plough the fields. The great Yü did not keep even his own body for his own benefit; he worked to drain the flood until one side of his body was paralysed. A man of ancient times, if he had benefited the Empire by the loss of one hair, could not [he] have given it; and if everything in the Empire had been offered to him alone, would not [he] have taken it. When no one would lose a hair, and no one would benefit the Empire, the Empire was in good order. (Graham 1990, 148) ${ }^{6}$

Against Confucian moral ideal of “qijia” (齐家, harmonizing the family), “zhiguo” (治国, managing/ regulating the state), and “pingtianxia” (平天下, bringing peace to the world), Yangzhu suggested individual should pay full attention to treasure their own lives and not put their lives into potential dangers by neither entering a besieged city (buruweicheng, 不入危城) nor holding service at the army (buchujunlü, 不处军旅). ${ }^{7}$ He was opposed to the Confucian use of conventional values as a tool to pursue longevity, riches, fame, and honor. Yang Zhu insisted that one should not allow oneself to be tied to material things (buyiwuleixing, 不以物 累形). ${ }^{8}$ Yang Zhu questioned the value of fame and honor in comparison to life: “If anybody cares for one’s own blame or praise so much by torturing his spirit and body, he will struggle for a name lasting some hundred years after his death. Can the halo of glory revive his dried bones, or give it back the joy of living” (Anton Forke 2012)? ${ }^{9}$ From Yang Zhu's viewpoint, “all fame is nothing but falsehood;”10 seeking for fame, riches, or honor, is to focus on externals. Focusing on externals will further result in the ignorance of one's internal self and allow one's true nature to be lost, and thus lead one to suffer the consequences in reality: “There are four things which do not allow people to rest: Long Life, Reputation, Rank, and Riches. Those who have them fear ghosts, men, power, and punishment. They are always fugitives. Whether they are killed or live, they regulate their life by externals" (Anton Forke 2012, 61-62). ${ }^{11}$ 
Suffering in reality will finally cause one's grief and misery and therefore make one to live an unhappy life. One's grief and feelings of misery cannot be released unless one's true nature is revealed and fulfilled; one's unhappy life cannot come to an end unless one's suffering in reality is ended. Therefore, a yearning of being oneself and a desire of returning to one's true nature will be always there and this will lead one to regret what he/she has done. ${ }^{12}$

It is clear that neither the Mohist “universal love” (jian’ai, 兼爱) based on the principle of equality and reciprocation, nor Confucian "graded love” (ren’ai, 仁爱) based on filial piety and benevolence, is akin to Yang Zhu’s "guiji” - a "self love” based on the natural principle indorsed by heaven and earth. Unlike Mohist "universal love" which takes social and state's interests as priority, or Confucian "graded love" that takes family interests as priority, Yang Zhu's "self love" is intended to be related to one’s own physical pleasure and mental happiness and therefore gives self a supreme position that surpasses the interests of both the family and the state by separating "ji” from family and state, and giving oneself an independent position of priority. Yang Zhu makes himself and his doctrine stand out from the mainstream of Chinese tradition. ${ }^{13}$

The structure of Yang Zhu's "guiji” yangsheng philosophy is very clear: "Ji" as an independent self entity distinguished from both family and society is right at the centre of Yang Zhu's nourishing life philosophy. This means, nourishing life is to adhere to one's true self.

Yen-Ping-Chung asked Kuan-Yi-Wu to cherish life. Kuan-Yi-Wu replied: "It suffices to give it its free course, neither checking nor obstructing it.” Yen-Ping-Chung said: “And as to details?” Kuan-Yi-Wu replied: “Allow the ear to hear what it likes, the eye to see what it likes, the noses to smell what it likes, the mouth to say what it likes, the body to enjoy the comforts it likes to have, and the mind to do what it likes.” (Anton Forke 2012, 43) ${ }^{14}$

There are two targets being embraced within Yang Zhu’s “guiji” practice: to keep one’s physical body and sensual organs in a satisfied condition, one's mind and heart in a happy mood, and one's emotions and feelings in a pleasant situation; two ways that have been used for ensuring the realization of the two targets: One is to keep one's true nature intact and the other is to keep one's genuine self in a protected situation; three methods have been used by Yang Zhu for keeping one's nature intact and protecting one's self in genuineness, they are: an inward seeking for one's internal nature and true self from within; a natural attitude toward life and death; and a freedom from attachments to any conventional values or external material pursuits.

From such a structure, it is hard to conclude that Yang Zhu's philosophy is a selfish doctrine which rejects an opportunity to sacrifice a single hair to benefit the whole world and it is even harder to determine that Yang Zhu enhances the idea of sacrifice of the interests of others for the benefit of oneself. In fact, as Graham has recognized, Yang Zhu "wants pleasure for other men as well as for himself." This can be seen clearly from the story of Tianmu-Shu that he does not only share his fortune with others but also leave nothing for himself in the end. ${ }^{15}$ In order to understand how and why Mencius' critique which is that "not to sacrifice one single hair for gaining a benefit as great as Empire" is a "proof of high-minded indifference to personal gain" (Guocheng Jiao $1989)^{16}$ rather than an evidence of extreme selfishness, we need to examine what the meanings of "ji" and "wo" are.

\section{The Meaning of “Ji" and "Wo"}

Although both "ji”" and "wo" can be translated as "oneself” in English, they do have different meanings in Chinese. In Xushen’s “Shuowenjiezi” (说文解字, Explaining and Analyzing Characters), “ji” (己), based on its look as a belly is interpreted as the "middle part of a body," to mean "oneself" as a holistic entity that is 
different from others; ${ }^{17}$ "wo" (我), in contrast, is interpreted as "one calls oneself." Since "wo" was a combination of two parts, "ge” (戈, weapon) and "shou” (手, hand) to mean a weapon in hand, "wo” was also identifiable with "sha” (杀, kill) in ancient time. ${ }^{18}$ According to Gu Yankui’s Dictionary of the Roots of Chinese Character, "ji” (己), from its structure, looks like a leading thread weaving through various silk threads so as to bind them together, to mean "weave," "tie up,” "bind,” or "distinguish.” Its original meaning refers to the middle palace where one's whole self is contained, to mean "oneself” or "one own;” its extended meaning is "to distinguish" and "to record." 19 Whereas, "wo" (我) in "oracle bone inscription” looks like "a saw or knife with sharp teeth" and so refers to either "saw alike instruments" or a "calling for oneself in front of other people;" "wo" also has an extended meaning as "kill."” Anxian Luo gave a more detail examination on "wo" when he examined Zhuangzi’s concept “wusangwo” (吾丧我). According to him, “wo” is not simply to mean one calls oneself, but to mean one calls oneself in front of others. Because in the eyes of others, there are not so many differences between individuals who term themselves as "wo;" however, for the person who calls himself/herself "wo," it does indicate a clear intension to bring himself/herself out as a distinctive unit that is different from others and needs to be defended. The reason why "wo" has equal meaning with weapon "ge" is that "wo" is an offensive weapon with a long handle. Although the exact reason for why "ge" and "wo" are developed together is hard to know, we still can catch its rough reason like this: "wo" is a protective "I" with a strong desire of peculiarity; "wo" will initiate an attack when I have a feeling of being offended. Since "wo" is not a defensive weapon with a short handle but rather an offensive weapon with a long handle, this indicates that "wo" will normally initiate an attack when one thinks there is an on-going offence, whether this assumption is true or not. ${ }^{21}$

Based on above interpretations, it is clear that "ji”" refers to an identifiable container where one's whole self is included from within. "Ji” is thus become a symbol to identify oneself as a holistic identity. Since "ji”" is merely an independent private entity separated from others or relationships, there will be neither a social/political relationship nor a moral/economical relationship with others attached to "guiji" acts. Whereas "wo" is connected to a relationship with others on one side and a weapon for attack and kill on the other side, therefore when people use "wo" to call himself/herself, it always indicates that one is intending to defend oneself (wo) by weapons that may bring harm to others. Because "guiji" is just to "treasure oneself" as a holistic entity and intends to keep one's own nature in an intact condition, "weiwo" means one will attack even kill others in order to protect one's own benefits. We can now conclude that "guiji" (treasure oneself) is not equal to "weiwo" (for oneself) at all. ${ }^{22}$ When Mencius uses "weiwo" to replace "guiji” to mark Yang Zhu's doctrine, it is clear that he is deliberately putting a selfish cap onto the head of Yang Zhu's tradition. From my viewpoints, Yang Zhu's "guiji” philosophy is not only a philosophy of "weiwo" (for one’s own benefits), but actually a philosophy of "feiwo" (非我, deny self) in terms of persuading individuals to give up their social profitable pursuits and encourage them to cut themselves off from all external attachments, including familial, social, and political profits, as well as one's economical and moral interests. This idea has been inherited and developed by Zhuangzi in his story of "wusangwo" (吾丧我, I abandon myself), and the "wo" that Zhuangzi intended to depart from or throw away, according to Anxian Luo, is the socialized external self and the reason why one should abandon this secular and socialized "wo," is for returning to one's true internal self. ${ }^{23}$ 


\section{Yang Zhu's Concept of “Ji” and “Guiji”"24}

In order to reveal the true nature of Yang Zhu's "guiji” philosophy, an examination of what is meant by "ji" in his understanding is very important. Unlike Sigmund Freud who defines "self" merely in terms of psychology, Yang Zhu discusses "ji” from three different levels: the physical and psychological levels as well as the spiritual level.

On the physical level, Yang Zhu connected “ji” with shen (生), the physical life of the individual, therefore, “guiji” for Yang Zhu, is to treasure one’s physical living body and allow it to live in a natural and happy way: "Always life is precious and death comes too soon. We must never forget that we are living this precious life, waiting for death which comes too soon; and to wish to impress others with your respect for propriety and duty, distorting your natural passions to call up a good name, in our judgment is worse than death" (Graham 1960, 145). ${ }^{25}$

As life is precious, everybody can only have one chance to live it, and therefore everybody should treasure it and never put it in danger. A Yangist would "enjoy this single life to the full, draining the utmost pleasure from life’s best years” (Graham 1960, 145). ${ }^{26}$ We can see this idea more clearly in chapter “guisheng” (贵生, treasuring life) of Lüshichunqiu,

The sages pondered over all things in the world and found that nothing is treasured more than life. Physical organs such as ears, eyes, nose, and mouth, they are merely servants of one's life. Thus, although ears like sound, eyes like colors, nose likes fragrance, and mouth likes flavour, they should be prohibited if they are going to harm one's life. ... Regarding to benefit, gaining a world is great enough yet one will not harm one's life to gain it, how could one let other things be prior to one's life? (Chen Qiyou 2002, 75) ${ }^{27}$

From the psychological level, similar to Freud, Yang Zhu also put spontaneous desires derived from one's physical need for survival and pleasure into the structure of "ji." Thus, to please one's physical body, to satisfy one's essential bodily and mental desires, and to keep one's emotions and feelings in a happy and wellbeing condition, are also essential for Yang Zhu's concept of “guiji.” In chapter “qingyü” (情欲, lust) of the Lüshichunqiu, how desires and emotions are essential for one's life is also discussed:

A human is born with avarice and desires. ... Therefore, the liking of the five sounds of the ears, the liking of five colors of the eyes, and the liking of five flavors of the mouth, are all desires. These desires are possessed by everybody, no matter if they are nobles or commons, stupid or wise, virtuous or immoral. Emotions and desires are the same in the lives of the Divine Farmer and the Yellow Emperor, as well as in the lives of the Jie and Zhou. (Chen Qiyou 2002, 86) ${ }^{28}$

Based on this, the author concludes that "one's life will have no difference from its death if one's ears could not like sounds, one's eyes could not like colous, and one's mouth could not like flavors” (Chen Qiyou 2002). ${ }^{29}$

Although both Yang Zhu and Freud have discussed their "ji”" or self from a psychological perspective, their conclusions on what is worthy of promotion with the true self are entirely different. Freud divides "self" into three parts, the pleasure-oriented "id" part, the conscience driven superego part, and the ego part as the balance between the id and the superego. Among them, only the id is what a person is born with; whereas, both ego and superego are formed after birth and development involve the experience of social relationships. The superego is perceived by the individual as the good part of the self, while the id is the dark unconscious side of the self. According to Freud, the id is unconscious by definition: "it is the dark inaccessible part of our personality" (Sigmund Freud 1933), and "most of that is of a negative character and can be described only as a contrast to 
the ego" (Sigmund Freud 1933); although "it is filled with energy reaching it from the instincts, but it has no organization, produces no collective will, but only a striving to bring about the satisfaction of the instinctual needs subject to the observance of the pleasure principle" (Sigmund Freud 1933, 105-6) ${ }^{30}$ He argues that the autonomous self is governed by desires and passions, and that these desires, even if we are not conscious them, will naturally steer our decisions. ${ }^{31}$ Unlike Freud, Yang Zhu regards these desires and passions as a part of one's internal nature which needs to be satisfied and taken care of. In this way, Yang Zhu strengthens the idea of autonomous self from the human nature perspective.

Why the enjoyment of one's sensual pleasure is so important for individual life has been discussed in the chapter of Yang Zhu in Liezi. ${ }^{32}$ According to the author, to achieve immortality is neither impossible nor necessary; to achieve longevity is hard and difficult. Even for someone who does live for a long life as hundreds of years, the unconsciousness of infancy and old age will take half of his/her life; the time he/she passes unconsciously while sleepy at night, and that which is wasted during wakefulness in the day also amounts to another half of the rest. Again pain and sickness, and sorrow and fear, fill up about a half, "so that he really gets only ten years or so for his enjoyment” (Anton Forke 1912). ${ }^{33}$ With the enjoyable part of human life so short, humans should treasure their lives and not waste them: "The men of the distant past knew that in life we were here for a moment and in death we were gone for a moment. Therefore they acted as their hearts promoted and did not rebel against their spontaneous desires" (Graham 1990, 140). ${ }^{34}$

From above discussion, it was clear that Freud's regarding of the inborn part of self as the dark side of self perceived by individual was entirely different from that of Yang Zhu who in contrast promoted this part of self as the perfect and pure authentic part of one’s self. For Yang Zhu's perspective, the social made "self" formed through various social relationships based on conventional values after birth was no longer the perfect essence derived from Dao, and indorsed by heaven and earth. This was due to its encounter with social pollution, and therefore this socialized self was the "wo" that should be refused or abandoned by oneself, the "ji." 35 Therefore, Yang Zhu encouraged people to cut off their ties to external material profits and gains, and entirely focus on personal enjoyment of sensual pleasure and one's internal spiritual transcendence. As Alan Fox suggests, "the Yangists believed that each individual must rely on their own intuition for guidance in protecting their integrity" (Alan Fox 2008, 362), ${ }^{36}$ because "the transcendentalists asserted that God was to be found in nature and in human beings, which was structurally consistent with Yangist notion of xing or 'nature,' and its relation to Tian or 'Heaven'” (Alan Fox 2008, 361). ${ }^{37}$

Different again from Freud who thinks the moral driven superego has nothing to do with inborn id, Yang Zhu insists that in the inborn human nature, one's intending of spiritual transcendence has already embedded from within. He states that although fine clothes, good food, music, and beautiful women are what a man would live for and where he can find happiness, "we cannot always have enough good clothes and food to satisfy us, cannot always be playing with women and listening to music" (Alan Fox 2008, 139), ${ }^{38}$ therefore, to find out what one's heart is longing for and what is one’s “xing” (性, innate nature) intending to do becomes more important content for Yang Zhu's nourishing life philosophy.

\section{Yang Zhu's “Xing” as the Core of the Self and the Root of Morality}

One of the greatest contributions of Yang Zhu’s philosophy is to connect "ji” to "xing” (性, human nature) and regard "xing” as the root of morality. According to Benjamin Schwartz (1989), 
The first reliable recorded usage of human nature is found in statements describing the doctrine of Yang Chu, and that in Yang Chu, it does not simply refer to innate "natural" properties in general but the particular propensity of human beings to pursue their own natural "desires" for health, long life, and freedom from anxiety. The only instruction which heaven inscribes us is the instruction to seek our own individual creaturely well-being. ${ }^{39}$ (Benjamin Schwarz 1989, 175)

Regarding what is meant by “xing,” Alan Fox (2008) suggests that,

The xing, which is mandated by tian, can be described as destiny as opposed to fate. The goal of life, according to this way of thinking, is to fulfill your destiny, your potential, and to be all that you can be, given your own peculiar, idiosyncratic combination of limitations and abilities. Again, in the most rudimentary sense, this refers to living out one's natural life span, although it eventually evolves into a more sophisticated model that accounts for the quality as well as the quantity of life. $^{40}$ (Alan Fox 2008, 363)

For the Yangist, in accordance with Graham, xing "is primarily the capacity, which may be injured by excess or damage from outside, to live out the term of life which Heaven has destined for man" (Graham 1989). ${ }^{41}$ Following Laozi, Yang Zhu also regarded "xing" as an internal human nature with pure and genuineness of character. Yang Zhu's concept of “xing” had close connection with Laozi’s understanding of the xing (essence) as the manifestation of the Dao. Laozi says, "When Dao manifested as a thing ... the essence of the thing is already endure, and the essence that enfolds within is extremely true and genuineness, and within this genuineness, there is trustworthiness and authenticity" (Zhu Qianzhi 1982). ${ }^{42}$ As the manifestation of Dao in personal life, "xing” therefore possesses perfect, pure, and authentic characteristics which are similar to that of Dao in Yang Zhu's thinking. In chapter "guisheng” of Lüshichunqiu, the author, apparently from Yangist school, mentions the relationship between the genuineness of Dao and the body when he discusses the Dao of Completion of the Body and Nourishing Life (wanshen yangsheng zhidao, 完身养生之道), “the genuineness of the Dao is for keeping the life of one’s body" (Chen Qiyou 2002). ${ }^{43}$ Because this perfect and pure "xing," as the true and internal "ji," is connected to the genuineness of the Dao, "guiji” for Yang Zhu is, on one hand, to keep one's "xing” intact, and on the other hand, to ensure one’s internal self in a genuine and an undisturbed condition.

To keep one's xing in an intact and genuine condition is so important that some Yangists even give it a position prior to a forced life. Lüshichunqiu recorded a saying from Zihuazi (子华子, a disciple of Yang Zhu) like this, "to keep one's life intact is the best, to keep one's life partially completed is the second, death is the next, and to live under force is the worst one" (Chen Qiyou 2002) ${ }^{44}$ Based on this, the author of chapter “Treasure Life”(guisheng, 贵生) of Lüshichunqiu, concludes that “to treasure life is not to life under force,” and "to live a life under force is worse than death" (Chen Qiyou 2002). ${ }^{45}$ So keeping one’s internal "xing” and true self is so important that a freedom of pursuing internal "xing” and a will to untie oneself from any external and material pursuits are also important for Yang Zhu's nourishing life philosophy. As "the first important Chinese thinker who develops a philosophy for the individual disinclined to join in the struggle for wealth and power” (Graham 1960), Yang Zhu points out that the full enjoyment of keeping one's nature intact will be "hindered by moral conventions which we obey from an idle desire to win a good reputation in the eyes of others and fame which will outlast our deaths" (Graham 1960). "What the will wishes to achieve is freedom and leisure, and if it is denied these, I will say man's nature is restricted" (Graham 1960). ${ }^{47}$ This liberty idea is not only inherited and further developed by Zhuangzi in his theory of absolute freedom, ${ }^{48}$ but also by the later Daoist practitioners for their practice of life preservation. 
One thing that needs to be addressed here is that Yang Zhu's challenge to conventional values does not lead to a moral nihilism. Schwartz suggests that "Yang Zhu's contribution to the entire discussion of Hsing may not at all have been the invention of the notion as a philosophic term, but rather his particular self consciously 'egoistic' interpretation of it” (Benjamin Schwartz 1985). ${ }^{49}$ Yang Zhu never suggests satisfying one’s natural inclinations at the cost of morality; in fact, Yang Zhu actually confirmed the legality of morality when he discussed the nature of humankind in comparison with the animals and said that "Men resemble heaven and earth in that they cherish five principles" (Benjamin Schwartz 1985). ${ }^{50}$ Although Yang Zhu did not discuss what these five principles were, through his discussion on human nature in comparison with the animals, it could be seen that "zhi" (智, intelligence) should be the first one: "Men resemble the other species between heaven and earth, and like them owes his nature to the Five Elements. He is the most intelligent of living things” (Graham 1960). ${ }^{51}$ Although this idea in Yang Zhu' chapter may not be directly from Yang Zhu as Graham indicated in his translation, it did show its difference from Confucian understanding of morality and intelligence. For example, Xunzi also discussed the importance of intelligence in the process of distinguishing humans from animals: "It is the faculty of intelligence that which enables people to develop prudence and foresight, and in turn consider the consequences of their action” (Zhao 2007). ${ }^{52}$ However, the functions of intelligence in Yang Zhu and Xunzi are different. The faculty of intelligence for Yang Zhu is for knowing the true human internal nature and self preservation, ${ }^{53}$ but for Xunzi is for drawing moral boundaries and following the moral principles invented by the ancient sage kings. Thus, although Xunzi did grant human desires as being a legitimate state and admitted that morality exists for the better satisfaction of human need to bring people long-term benefit; ${ }^{54}$ he never like Yang Zhu, connected morality with human internal nature.

Yang Zhu discussed his second moral principle of "not getting entangled with things" in a story of Tuan-mu-shu. Through praising how Tuan-mu-shu sent off the remains of his table to his clansmen, his fellow citizens, how he distributed what these did not eat throughout the whole kingdom, and when he reached his sixtieth year of age how he further gave up his household and distributed all his treasures, pearls and gems, carriages and address, and his concubines and female attendants, ${ }^{55}$ Yang Zhu showed what the virtue of "entangling with nothing” was and how the enjoyment of individual life was neither based on a violation of the essential moral principles of being generous to others, nor the basis of sacrifice of others. The other three moral principles also discussed by Yang Zhu are the necessity of compassion, sympathy, and benevolence towards people who are in need:

There is an old saying, we must pity the living and part with the dead. This is a good saying. Pity does not merely consist in an unusual feeling. So we may give the feverish rest, satiety to the hungry, warmth to the cold, and assistance to the miserable; but for the dead, when we have rightly bewailed them, to what use is it to place pearls and jewels in their mouths, or to dress them in state robes, or offer animals in sacrifice, or to expose effigies of paper? (Anton Forke 2012, $42)^{56}$

In this passage, Yang Zhu gave a very clear message: Pursuing one’s personal enjoyment should not be based on the rejection of taking care of others, including the dead; Yangsheng (nourishing life) should include both the nourishing of one's own life and that of others. Inherited Laozi’s ideal that "all things of the universe worship Dao and exalt De," but "That Dao is worshipped and De is exalted is not due to anyone's order but is so of its own nature” (Zhu Qianzhi 1982); ${ }^{57}$ Yang Zhu never discouraged one’s pursuing purity and true virtue. What Yang Zhu against was to "do good in a false way" or pursue a false virtue. ${ }^{58}$ Based on this, Graham states, "the yongist is at any rate where an individualist is concerned to benefit his own person and leave others to do 
the same” (Graham 1989). ${ }^{59}$ Thus, it is a lack of evidence to mark Yang Zhu yangsheng philosophy with moral nihilism.

In fact, from my point of view, Yang Zhu has actually suggested a new moral standard here: To follow one' internal nature is not evil but a true virtue; the spontaneous internal nature should be where the true morality comes from. Any so called "moral principle," no matter whatever name it is given, if it is a source of painful human vexation, should be not regarded as a true morality, but false morality. In Yang Zhu's account, only those authentic virtues derived from true human internal nature and those essential moral principles can represent the truly important concerns of human life that be regarded as true morality; this is because only the true virtues can bring peace and true happiness to the people. Otherwise, any superficial virtues and conventional standard of morality should be named as a false morality because the conventional and formal standards of morality and behavior may convey/conduct something bad: They are "superficial virtues" that may stand accused of crowding out more "substantial and authentic" moralities; and that the affected manners and empty courtesies are behaviors that "consist in unrecoverable waste of human and natural resources" (Alan Fox 2008). ${ }^{60}$ In this way, Yang Zhu leads the definition of virtue and morality to a new direction.

To connect human nature with a heavenly indorsed authentic quality and genuineness, this has been inherited and developed by Mencius in his theory of "human nature is good.” In the mean times, Yang Zhu's inward searching methodology for seeking for individual's true nature was also inherited and developed by Mencius in his moral cultivation theory. For Mencius, because the capacity to understand and apply moral principles which can distinguished humans from animals was intrinsic to human nature: "The feeling of commiseration belongs to all men; so does that of shame and dislike, that of reverence and respect, and that of approving and disapproving” (Yanxia Zhao 2007), "benevolence, righteousness, propriety, and knowledge are not infused into us from outside; we are certainly furnished with them” (Yanxia Zhao 2007). ${ }^{61}$ Thus, seeking morality from within became an important method of Mencion personal moral cultivation.

Yang Zhu's connecting "xing” with Dao and "ji” leads him to a natural attitude toward life and death. Since one's "xing" is manifestation of Dao in a person and the nature of Dao is to follow the Nature of Spontaneity, the "xing" as the core of one's self should also be identifiable with Nature. Thus, although life is treasure of worth, yet as life itself is just a natural process, one should not regard oneself as the owner of one's body alone, because the body also belongs to the whole universe. Using Yang Zhu's own words, life should be nothing but a natural process of fulfilling one’s destiny: “For I, when I am born, must complete it” (Yang Bojun 1985). ${ }^{62}$ Based on such an understanding, Yang Zhu suggests that one must live in a natural way and should neither artificially prolong one's life nor intend to injure or murder it.

Zhuangzi inherits this natural attitude to life and death in its entirety. For Zhuangzi, both life and death are forms of natural transformation, and if we trace the beginning of life, there will be no life before the birth of life, neither its physical form nor its vital energy that a formation of life needs to exist. "Her breath wrought a transformation and she had a body. Her body wrought a transformation and she was born. Now there is yet another transformation and she is dead. She is like the four seasons in the way that spring, summer, autumn, and winter following each other” (Martin Palmer 1996, 151). ${ }^{63}$ The only difference between Yang Zhu's and Zhuangzi's ideas of how to live in accordance with one's nature is that, Yang Zhu suggests a movement from the action of external pursuit to that of internal seeking: “They regulate their life by inward things” (Anton Forke 2012); ${ }^{64}$ while Zhuangzi, on the other hand, suggests people should do nothing including internal cultivation: "I regard actionless action as worthy of being called happiness, though the ordinary people regard it 
as a great burden ... Perfect happiness is keeping yourself alive, and only actionless action can have this effect” (Martin Palmer 1996). ${ }^{65}$

Yangzhu's natural attitude toward life and death has influenced traditional Chinese life-death philosophy profoundly, and has also inspired people to think about what's the meaning of human life: to choose to live in an artificial prolonged life with suffering and indignity or to choose to leave one's life and death to occur in a natural way? This is still a big question even today.

\section{Yang Zhu's “Ji” and the Western Understanding of "Self”}

There are always ongoing debates on what is meant by Yang Zhu's “ji” and how it relates to the Western idea of "self." From a Western perspective, ideas of "selfhood" are "squarely pitched between those who deny the agency of human subjects and argue in favour of the person's determination by social structures, and those who celebrate the authenticity and creativity of the self, on the other" (Anthony Elliot 2007). ${ }^{66}$ According to Xinzhong Yao, the self has been for a long time and for a great deal used in the follow sense: In the metaphysical sense, the self is a constant unchanging substance by which each individual is identified or distinct entity differentiated as opposed to the rest of world; in the epistemological sense, the self is the thinking or contemplating interior core either termed as the soul or as the mind, differentiated from one's physical reality; in the psychological sense, the self is compound of feelings, emotions, memory, will, and knowledge. It is neither the object nor the subject, but a stream of various consciousness or the sum of these inner state. ${ }^{67}$

By connecting Yang Zhu philosophy to "weiwo," it seems that both Mencius and some modern sinologists deny this Western understanding of self having anything to do with Yang Zhu's doctrine; Mencius denies it through directly relating "weiwo" to the criticisable selfish interests or benefits, while some modern sinologists deny it by interpreting "wo" as something bigger than oneself. ${ }^{68}$ However, if we do not connect the western "self” with "wo" but Yang Zhu's notion of "ji," it can be seen that these denials are farfetched. Yang Zhu’s “ji," though it has its own distinctiveness as is shown in comparison with Freud, it still has similarity with its Western counterpart.

First, similar to the Western "self," Yang Zhu's "ji” also acts the identification of an individual. Max Weber declares that the traditional Chinese lacks "inward care" and lived by a process of "adjustment to the outside," so in such a society, "an individual's place and 'self' are not defined by nature but one's social standing or relationships with others" (Max Weber 1964). ${ }^{69}$ This statement is simply not true in the case of Yang Zhu. For Yang Zhu, although all humans in terms of differences to animals do have a common human nature, that is, they must follow the five essential moral principles indorsed in human's "xing” by "tian"; every human individual does have their own identifiable nature. This individualized nature is the true or internal nature of oneself derived from the Dao, therefore, in the metaphysical sense, "ji," same as "self," is also a constant unchanging substance, by which each individual can be identified as a distinctive entity. In the psychological sense, Yang Zhu's “ji," is also similar to the Western "self” to be an interior core combined by one's special desires and feelings based on one's special physical structure and emotional disposition. In this way, Yang Zhu strengthens the idea of the autonomous self as an aspect of human nature. Based on this, Emerson states that Yang Zhu's contribution to Chinese philosophical history is his discovery of the individual body. ${ }^{70}$

However, there are more differences between Yang Zhu's concept of "ji" and the Western concept of "self." Different from the traditional Cartesian concept of "self" as a thinking that is differentiated from the 
body, ${ }^{71}$ Yang Zhu's “ji” never "cut off from its relationship to the body” (Anthony Kenny 1988) regarded physical life as an integrated part of "ji” that needs to be satisfied and taken care of.

Different again from traditional Western understanding of "self" as an absolute independent personal unit that is isolatable from the rest of the world, Yang Zhu's "ji” has connection not only with society, but also with nature: “Ji," as self identity, is connected to one's internal nature endorsed by Dao, and in the mean time as a human individual, "ji" also needs to follow true moral principles derived from the law of the Heaven and Earth.

Different from Western postmodernist philosophy where self is "no longer regarded as deep identity in personhood which makes a person a specific person" (Anthony Kenny 1988) and "no longer viewed as clearly identifiable entity either of an agent or as a subject," but "taken as the process of self-creation" (Anthony Kenny 1988), ${ }^{73}$ Yang Zhu's “ji” is a subject with mobility who is able to use one's intelligence and freewill to identify what is true happiness to him/her true self, and it is also an object that can be observed and identified with one's true internal nature. Thus, although Yang Zhu's emphasis on physical pleasure and individual happiness seems to have similarity with Western individualism, because of its stress on an internal seeking and withdrawal from external material gaining, Yang Zhu's individual focus doctrine is fundamentally difference from that of Western individualism: It is not defined and restrained by materialism, but rather imparted to the preservation of the internal self. For Yang Zhu, to find individual's internal self or one's own nature is necessary. As a living being, everybody has one's own sense, one's own thinking mode, and one's own special physical form, and all these are connected to one's internal nature. This internal nature is original and genuine to one's true self and true happiness, thus it needs to be satisfied. Based on this, Schwartz suggests that Yang Zhu's "natural” tendency implanted in man by Heaven is the tendency to live out one's own life in health, in the absence of anxiety, and in the moderate satisfaction of one's sensual desires. This involves as little entanglement as possible with the social order, but may also involve avoidance of hedonist excesses. ${ }^{74}$

\section{Modern Relevance of Yang Zhu's Yangsheng Philosophy}

According to John Emerson, recent studies of the rise of Western individualism have found many of the elements that are presented during the era of Yang Zhu, for example, an increasingly efficient despotism, the reduction of complex communal obligations to more explicit legal and economic obligations, self-discipline on the model of government control, and a naturalistic and bodily emphasis. ${ }^{75}$ All these make Yang Zhu's yangsheng philosophy more relevant toward the modern society.

First, Yang Zhu's concept of "ji” can provide a great inspiration for a Chinese understanding of "self." Unlike the integral Western identity where the self will possess a power that can enter various external relationships freely, the "self" in traditional Chinese society is "plural, diffuse, empty, and implicated with various 'others." 76 Although under the western influence, Chinese society is no longer like the ancient society that Yang Zhu lived, where the essential use of what defined a person's personality was dominated by its so called familial, social, and political roles; as a society that had a long history under the heavy influence of Confucianism, individual motivation and choice related to self interests and inner nature were normally hard to be promoted even in modern China. Therefore, it is still not easy to have an absolute independent and separated self existing as an individual entity in modern Chinese society. As John Emerson identifies, "The emptiness of the self rises from the fact that these relationships monopolize a person's life: the individual's area of exclusive 
ownership, personal control, and free choice, as well as the space within which individuals interact freely as individuals, are small or nonexistent” (John Emerson 1996, 537). ${ }^{77}$

In such a circumstance, Yang Zhu's discovery of the "ji” as the identity of oneself and the unity of physical body and spiritual setting, indeed has opened a new window for modern Chinese to think what is the aim and meaning of human life, as John Emerson (1996) argues,

The "discovery of the body," wherever it occurs, is part of a reconfiguration of the self/other, individual/group, and private/public relationships, leading to a new sense of self: unified and not plural, detachable from context, freed from attachments and identification, autonomous and capable of rational choice, and unambiguously located in space and time. The ancestral spirits lose most of their reality and clan relationships become less dominant. (John Emerson 1996, 538) ${ }^{78}$

Secondly, Yang Zhu's concept of "ji”" as a holistic unity needed to be discovered from within can also bring inspiration to Western society. The self of Western individualism encounters two serious problems: One is materialism with outward seeking; the other is the missing of the pursuit of spirituality resulted by secularization.

Materialism intends to use one's physical body as a tool to pursue external material interests such as wealth, social status, moral reputations, and political honor. This obviously will result in ignorance of what one's true body needs in terms of physical and spiritual wellbeing. By defining self as the combination of physical life, psychological self identity, and mode of spirituality, Yang Zhu enhances a life cherishing philosophy based on the satisfaction of both one's physical and psychological, as well as spiritual needs.

Alongside the popularity of materialism and secularization, human pursuit of spirituality has declined. External material pursuit has become the only aim of more and more individual lives. Regarding all public identifications as an external hindrance to the realization of one's true self, Yang Zhu promotes a notion of the good that pertains only to the enjoyment of private life, and a notion of virtue which is only related to the cultivation of one's own true nature based on finding of one's true need. This is greatly relevant to modern society. The popularity of external seeking materialism has already made individuals only focus on material gaining and forget what is the most important for physical and psychological health and spiritual wellbeing, and it has also made individuals lose their original internal self and aim of life; all these in turn make their minds full of worry, anxious, and fear. Yang Zhu's philosophy encourages people to ignore material pursuits and focus on personal physical pleasures and inward spiritual cultivation, which may be able to provide an effective way to relieve people from suffering mental disorder.

Finally, Yang Zhu advocated a natural attitude toward life and death and regarded both life and death as parts of natural process that need to be equally enjoyed and completed. Based on this premise, Yang Zhu discouraged both the artificial prolonging of life and suicide. This could also provide inspiration to modern society. Although life is a treasure, which is worthy to be celebrated and needs to be fulfilled as well as carefully protected, life comprises of birth and death, so both life and death should be equally as necessary experiences for people rather than that a position of one is loved and the other is hated. Therefore, neither life nor death but a natural and quality of life should be the aim of cherishing life, as Yang Zhu stated,

Morbidly to cultivate this cause of vexation, unable to get rid of it, and so having a long but very sad life of a hundred, a thousand or ten thousand years, is not what I call cherishing life. But to check this source of obstruction and with calm enjoyment to await death for a day, a month, or a year or ten years, is what I understand by enjoying life. (Anton Forke 2012, 44) ${ }^{79}$ 
In modern society people not only abuse their own bodies by taking drugs and using their own bodies as a machine tool, but they also poison their bodies with alcohol and overeating, and some even murder themselves by committing suicide. Others lose confidence and consciousness of their original selves for the purpose of chasing fashion; many people undergo plastic surgery and become obsessed with slimming for the purpose of parading one's wealth; many chase after consuming luxury just for the purpose of pleasure; many people lead a befuddled life, indulging in corrupting lifestyle. Under such a lifestyle, some lives have become abnormal.

Medical Science, in order to show its power and victory, has appointed its sharp knife towards natural life forms. To retain life forms in their original condition has been challenged by new developed life sciences and technology such as, genetic engineering, cell engineering, tissue engineering, protein engineering, stem cell technology, transgenic technology, clone technology, and reproduction control technology in order to show what modern science is able to do. Hospitals sometimes choose over treatment of patients in order to keep them alive, even if their living life will be worse than death. Modern life ethics and medicine ethics have given rise to many debates which are connected to Yang Zhu's attitude to life and death. For example, does an individual have the right to choose how to end their life? Is it moral for a hospital/offspring, for either good purpose (e.g., filial piety or humaneness) or a bad purpose (e.g., medical income or financial benefits) to use modern medical tools to keep someone alive even though a natural death maybe better for them? Is it moral if people want to help a person to end their suffering by ending their lives? All these questions can be found direct answers from Yangzhu's natural attitude to life and death.

People may argue that Yang Zhu's "guiji” Yangsheng cannot be practiced by the real human society, as moral values and communal obligations have become part of the self that has developed subsequent to birth as Freud has argued; as that the society is so important for humans to be on the top of the food chain that humans have to live in society and deal with social relationships? To keep a society in a good function, certain obligations have to be created for individuals to follow. To encourage people to follow the social principles, conventional values have to be promoted as an award to attract people's sacrifice of their true natures for the interests of the family and the society or the country. However, as many of us have already recognized, two obvious problems will emerge when people follow conventional values: First, different rules practiced by different countries, cultures, and religions may contradict to each other, thus which one is right might be a question for individuals to choose; and in the mean time, regulations established by various religions, societies, and political parties may no longer be appropriate for the purpose of protecting the true happiness of human individuals, but rather for the order, power, and benefit of the religion, the society, and the party. In such a circumstance, the established regulation may no longer provide essential moral principles that can benefit all humans, but become an external force for social control and exploitation. If individuals bind themselves to such a value system without independent thinking and follow a call from a particular society without consulting their heart from within, they may become involved in some insane conflicts that are against their own innate nature. Under the guidance of false moral principles, violence, terrorism, and conflicts between people and countries will get more and more severe. In such a situation, there will be neither peace among societies and countries, nor a calm mind in the individuals. If Yang Zhu's yangsheng philosophy, based on self care and keeping one's innate nature intact is practiced by politicians, and if each person's own distinctive nature can be recognized and respected, external and international conflicts will be dramatically reduced and the violence and terrorism that result from hate and revenge will be eradicated. If everybody/every country can focus on their internal business and internal cultivation based on their own nature, and not focus on disturbing, intervention, and the 
control of other countries, then the world could be really in peace. So Yang Zhu's suggestion should alert and inspire not only the modern philosophical thinkers, but also the political thinkers.

\section{Notes}

1. Yang Zhu is Yangziju in the Book of Zhuangzi, and Yangsheng in the Book of Lüshi Chunqiu (吕氏春秋) and he was born in the State of Wei at the Warring State Period time, and was a disciple of Lao Dan [see, Jiao Guocheng, "Yang Zhu Xuepai Weiwo Zhuyi Bianxi” (杨朱学派 “为我主义” 辨析), Zhongguo Renmin Daxue Xuebao (中国人民大学学报), Vol. 6, 1989, p. 89].

2. Yang Zhu’s ideas were only scattered in a few books, such as Mencius, Zhuangzi, Hanfeizi, Lüshichunqiu (吕氏春秋), Huainanzi (淮南子), Fayan (法言), Lunheng (论衡), and Liezi (列子), and even in such sources, Yangist philosophy is recorded as an objective of criticism rather than reasonable thought.

3. Lüshichunqiu, Book 5, chapter “bu er” (吕氏春秋·审分览第五·不二).

4. In chapter “fan xun lun” of Huainanzi (淮南子.氾训论), it says, 兼爱尚贤, 右鬼非命, 墨子之所立也, 而杨子非之。 全性葆真，不以物累形，杨子之所立也，而孟子非之。

5. Guocheng Jiao, “Yang Zhu Xuepai Weiwo Zhuyi Bianxi” (杨朱学派 “为我主义” 辨析, Analysis on Yang Zhu School’s Weiwo-ism), 中国人民大学学报, 第六期, 1989, p. 89.

6. Chapter "Yang Zhu” of Liezi, in A. C. Graham (trans.), The Book of Lieh-tzǔ: A Classic of Tao, Columbia University Press, 1990, p. 148.

7. “Celebrated School” in Han Feizi (韩非子·显学).

8. Chapter of “Fan Lun Xun” of Huainanzi (淮南子·氾论训).

9. Yang Chu's Garden of Pleasure, translated from Chinese by Professor Anton Forke with an introduction by Hugh Granmer-Byng, New York: E.P. Dutton and Company, 1912; Published by Forgotten Books 2012, chapter XV, p. 59-60.

10. Yang Chu's Garden of Pleasure, Anton Forke, 1912; Published by Forgotten Books 2012, p. 38.

11. Yang Chu's Garden of Pleasure, Anton Forke, chapter XVII, 2012, pp. 61-62.

12. Yang Chu's Garden of Pleasure, chapter I, p. 37.

13. As a culture that is derived from agriculture background, Chinese culture has a tradition of emphasis on family and society from far antiquity. Confucius have made a great change by shifting human's focus from one's clan to one's family and from filial piety to one's dead clan ancestor to one's living parents (Yanxia Zhao, Father and Son in Confucianism and Christianity, Sussex Academic Press, 2007, p. 21), however, both himself and his followers never had intension to separate oneself from his family and society. It was Yang Zhu who made self become an independent entity separated from both clan and society.

14. Yang Chu's Garden of Pleasure, chapter VIII, p. 43.

15. Yang Chu's Garden of Pleasure, p. 136-37.

16. Hanfizi (韩非子·显学), see Guocheng Jiao, “Yang Zhu Xuepai Weiwo Zhuyi Bianxi” (杨朱学派 “为我主义” 辨析 Analysis on Yangzhu School’s Weiwo-ism), 中国人民大学学报, 第六期, 1989, p. 90.

17. Duan Yucai, Shuowei Jiezi Zhu (说文解字注), Shanghai Guji Chubanshe (上海古籍出版社), 1981, p. 741.

18. Duan Yucai, Shuowei Jiezi Zhu (说文解字注), 1981, pp. 632-33.

19. Gu Yankui, Hanzi yuanliu zidian (汉字源流字典), Huaxia Chubanshe, 2003, p. 35.

20. Gu Yankui, Hanzi yuanliu zidian (汉字源流字典), 2003, p. 280.

21.Anxian Luo, “Interpretation of Zhuangzi’s ‘wu sang wo”” (庄子 “吾丧我”之义解), <http://confucian.ruc.edu.cn/ show.php?id=1210>, 13 Sep., 2013.

22. The Works of Mencius, 7A: 26.1 (孟子·尽心上), see The Four Books, Trans., James Legge. Culture Book Co., 1992. p. 956.

23. Anxian Luo, “Interpretation of Zhuangzi’s ‘wu sang wo”” ( 庄子 “吾丧我”之义解, 2013).

24. Yang Zhu’s idea of guiji had been inherited by Zhuangzi in his idea of quanshengbaoshen (全生保身, preservation of life) in chapter 3 of Zhuangzi, “The Secret of Nourishing Life” (养生主), where Zhuangzi discussed how one can through pursuing one's middle course to preserve one's life and to live for an allotted life span. Similar to Yang Zhu, Zhuangzi here also regarded to keep one's life in a natural condition as the target of one's life. However, from discussions of Zhuangzi in other chapters, such as in chapter 4 “the Human World” (人间世), it was clear that different from Yang Zhu's guiji which put more focus on keeping one's internal nature intact through encouraging one living in a natural condition, while Zhuangzi's quansheng put more emphasis on the preservation of one's physical life through living in an undisturbed natural condition. Yang Zhu's emphasis on xing (性 nature) and Zhuangzi's emphasis on physical ming (life span) are inherited and developed by the later Daoist religion into a doctrine of dual-cultivation of xing and ming in Daoist yangsheng exercise. Although condemning Yang Zhu's guiji as selfishness, yet Mencius actually inherited Yang Zhu's idea of human internal nature being good and further developed it into his famous 
theory of "human nature is good.” For Mencius, they reason why individual need moral cultivation was not because human nature was bad, but because one had lost one's good heart. Moral cultivation is to seek the lost good heart. Xunzi, on the other hand, although claimed that "human nature is evil," his morality cultivation was actually for the maximum ensuring of individuals' long term benefit and the ultimate satisfaction of individual's essential desires that were derived from their inborn nature.

25. Chapter "Yang Zhu” of Liezi, in A. C. Graham (trans.), The Book of Lieh-tzǔ: A Classic of Tao, Columbia University Press, 1960, p. 145.

26. Chapter "Yang Zhu” of Liezi, in A. C. Graham (trans.), The Book of Lieh-tzú: A Classic of Tao, 1960, p.145.

27. Chapter “Guisheng” (贵生), Zhongchunji di er (仲春纪第二), Chen Qiyou, Lüshichunqiu xin jiaoshi (吕氏春秋新校释), shanghai guji chubanshe (上海古籍出版社), 20.2, p. 75.

28. Chapter “Qingyu” (情欲), in session of “Zhongchun ji di er” (仲春纪第二), Chen Qiyou, Lüshichunqiu xin jiaoshi (吕氏 春秋新校释), 2002, p. 86.

29. Chapter “Qingyu” (情欲), in session of “Zhongchun ji di er” (仲春纪第二), Chen Qiyou, 2002, p. 86.

30. Sigmund Freud, New Introductory Lectures on Psychoanalysis, Penguin Freud Library 2, 1933. p. 105-6.

31. Sigmund Freud, Complete Psychological Works of Sigmund Freud Vol. 23, Vintage Classics, 2001.

32 Although the authenticity of Liezi being the source of the Pre-Qin source has been questioned by some scholars [See Michael Loewe (ed.), Early Chinese Texts: A Bibliographical Guide, Institute of East Asian Studies, 1994, p. 300Mich], as A.C. Graham recognized, "there is evidence that the editor of the Lieh-tzu has expanded the hedonist document with five additions alternating with its five sections, and the first three of these are from older sources and concern the historical Yangzhu" (see The Book of Lieh-tzú: A Classic of Tao, New York: Columbia University Press, p. 136), thereby it is still an important sources for us to understand Yangzhu's idea of Yangsheng.

33. Yang Chu's Garden of Pleasure, translated from Chinese by Professor Anton Forke with an introduction by Hugh Granmer-Byng, New York: E.P. Dutton and Company, 1912; published by Forgotten Books 2012, Chapter III, p. 39.

34. Chapter "Yang Zhu" of Liezi, in A. C. Graham (trans.), The Book of Lieh-tzǔ: A Classic of Tao, Columbia University Press, 1960, p. 140.

35. Yang Zhu's understanding of "ji” is also different from that of Confucianism. Similar with Freud's superego, Confucian "ji" is always connected to moral personality. For example, in Analects XLV, when Confucius was asked by Zilu of what constituted junzi (the superior man), he answered “xiu ji yi jing (修己以敬, to cultivate oneself in reverential carefulness), xiu ji an ren (修己安人, to cultivate oneself so as to give rest to others), and xiu ji yi an baixing (修己以安百姓, to cultivate oneself in order to comfort all the people)." Here "ji”" is connected more with moral self rather than biological self.

36. Alan Fox, "Guarding What Is Essential: Critiques of Material Culture in Thoreau and Yang Zhu," Philosophy East and West, Vol. 58, No. 3, University of Hawaii Press, July 2008, p. 362 of pp. 358-71.

37. Alan Fox, “Guarding What Is Essential: Critiques of Material Culture in Thoreau and Yang Zhu,” 2008, p. 361.

38. Alan Fox, "Guarding What Is Essential: Critiques of Material Culture in Thoreau and Yang Zhu,” p. 139.

39. Benjamin Schwartz, World of Thought in Ancient China, p. 175.

40. Alan Fox, “Guarding What Is Essential: Critiques of Material Culture in Thoreau and Yang Zhu,” p. 363.

41. A.C. Graham, Disputers of the Tao, Philosophical Argument in Ancient China, Open Court, 1989, p. 56.

42. Laozi, Dao De Jing, chapter 21, in Zhu Qianzhi, Laozi qiaoshi, Zhonghua shuju, 1982, pp. 88-9.

43. Chapter “Guisheng” (贵生), in “Zhongchunji di er” (仲春纪第二), in Chen Qiyou 2002. p. 76.

44. Chapter “Guisheng” (贵生), in “Zhongchunji di er” (仲春纪第二), 子华子曰: “全生为上，亏生次之，死次之，迫生 为下。” Chen Qiyou, 2002. p. 76.

45. Chapter “Guisheng” (贵生), in “Zhongchunji di er” (仲春纪第二), Chen Qiyou 2002, p. 77.

46. A. C. Graham, in The Book of Lieh-tzŭ: A Classic of Tao, New York: Columbia University Press, 1960, p. 135.

47. A. C. Graham, in The Book of Lieh-tzǔ: A classic of Tao, 1960, p. 142.

48. Zhuangzi has shown his contempt for conventional values in a similar but more radical way to Yang Zhu when he says, what the whole wide world values are riches, position, long life, and fame. What bring happiness are good time for oneself, fine foods, beautiful clothes, lovely sights, and sweet music. What are despised are poverty, meanness, untimely death, and a bad reputation. What are considered sour are a lifestyle which gives the self no rest, a mouth which never has fine foods, a body without good clothes, eyes that never see upon lovely views, and an ear that never hears sweet music. Those who cannot get these things become greatly agitated and fearful. .... Now, when ordinary people attempt to find happiness, I am not sure whether the happiness found is really happiness or not (The Book of Chuang Tzu: A New Complete Translation of the Classic Taoist Text, trans., Martin Palmer with Elizabeth Breuilly, Arkana: Penguin Books, 1996, p. 150-51).

49. Benjamin Schwartz, World of Thought in Ancient China. Cambridge: Harvard University Press, 1985. p. 179.

50. Yang Chu's Garden of Pleasure, 2012, chapter XVI, p. 60.

51. A.C. Graham, in The Book of Lieh-tzǔ: A Classic of Tao. New York: Columbia University Press, 1960. p. 153.

52. Yanxia Zhao, Father and Son in Confucianism and Christianity: A Comparative Study of Xunzi and Paul. Brighton and Portland: Sussex Academic Press, 2007, p. 40.

53. A.C. Graham, in The Book of Lieh-tzǔ: A Classic of Tao, New York: Columbia University Press. 1960. p. 153.

54. Yanxia Zhao, Father and Son in Confucianism and Christianity: A Comparative Study of Xunzi and Paul, Sussex Academic Press, 2007, p. 39.

55. Yang Chu's Garden of Pleasure, 2012, chapter X, p. 50. 
56. Yang Chu's Garden of Pleasure, chapter VII, p. 42.

57. Laozi, Dao De Jing, chapter 51, in Zhu Qianzhi, Laozi jiaoshi, Zhonghua shuju, 1982, p. 203.

58. Yang Chu's Garden of Pleasure, chapter V, p. 41.

59. Graham, Disputers of the Tao, 1989, p. 59.

60. Alan Fox, 2008, p. 367.

61. Mencius 6A 6, also see Yanxia Zhao, 2007, p. 38.

62. Yang Bojun, Liezi jishi, Zhonghua shuju, 1985, p. 230.

63. “Perfect Happiness.” Chapter 18, The Book of Zhuangzi, translated by Martin Palmer, Penguin Books, 1996, p. 151.

64. Yang Chu's Garden of Pleasure, chapter XVII, Anton Forke, pp. 61-62.

65. The Book of Chuang Tzu: A New Complete Translation of the Classic Taoist Text, trans., Martin Palmer with Elizabeth Breuilly, Arkana: Penguin Books, 1996, p.151.

66. Anthony Elliot, “Concepts of the Self.” Key Concepts 2nd ed. Cambridge UK/Malden MA: Polity Press, 2007, p. 13.

67. Xinzhong Yao, "Self Construction and Identity: the Confucian Self in Relation to Some Western Perceptions" in Asian Philosophy, Vol. 6 No. 3, 1996, p. 180.

68. For example, John Emerson argues that since “wo” in Chinese can be either refer to me or us, Yang Zhu's idea of "weiwo" can be used to mean speaking either for oneself or for one's family or clan, and therefore it is not at all certain that Yang Zhu and his followers rejected the burdensome obligations of the Chinese family ("Yang Chu's Discovery of the Body" in Philosophy East and West, Vol. 46, No. 4, 1996, p. 549-50); while for A.C. Graham, Yang Zhu "can justly claim to be concerned for life in general, not just his own” (Disputers of the Tao: Philosophical Argument in Ancient China, Open Court Publishing CO, U.S., 1989, p. 59).

69. Max Weber, The Religion of China: Confucianism and Taoism, New York: Macmillan, 1964, pp. 234-5.

70. John Emerson, "Yang Chu’s Discovery of the Body.” Philosophy East and West, Vol. 46, No. 4, 1996.

71. Anthony Kenny, The Self, Milwaukee, Marquette University Press, 1988, p. 7.

72. Anthony Kenny, The Self, 1988, p.7.

73. Anthony Kenny, 1988, p. 52.

74. Benjamin Schwarz,1989, p. 179.

75. John Emerson, “Yang Chu’s Discovery of the Body.” Philosophy East and West, Vol. 46, No. 4, 1996, p. 564, note 71.

76. John Emerson, "Yang Chu’s Discovery of the Body.” Philosophy East and West, Vol. 46, No. 4, 1996, p. 536.

77. John Emerson, "Yang Chu’s Discovery of the Body.” 1996, p. 537.

78. John Emerson, 1989. p. 538.

79. Yang Chu's Garden of Pleasure, Anton Forke, 2012, chapter VIII, p. 44.

\section{Works Cited}

Elliot, Anthony. "Concepts of the Self.” Key Concepts 2nd ed. Cambridge UK/Malden MA: Polity Press, 2007.

Emerson, John. "Yang Chu’s Discovery of the Body.” Philosophy East and West Vol. 46, No. 4, 1996. pp. 533-66.

Forke, Anton (trans.). Yang Chu's Garden of Pleasure. New York: E.P. Dutton and Company, 1912; Republished by Forgotten Books, 2012.

Fox, Alan. "Guarding What Is Essential: Critiques of Material Culture in Thoreau and Yangzhu.” Philosophy East and West Vol. 58, No. 3. Hawaii: University of Hawaii Press, 2008. pp. 358-71.

Freud, Sigmund. New Introductory Lectures on Psychoanalysis. New York and London: Penguin Freud Library 2, 1933.

Complete Psychological Works of Sigmund Freud Vol. 23. London: Vintage Classics, 2001.

Graham, A. C. Later Mohist Logic, Ethics, and Science. Hong Kong and London: Chinese University Press/SOAS, 1978.

Disputers of the Tao: Philosophical Argument in Ancient China. U.S.: Open Court Publishing CO., 1989.

Kenny, Anthony. The Self. Milwaukee: Marquette University Press, 1988.

Legge, James. The Works of Mencius, in The Four Books. Trans. James Legge. Beijing: Culture Book Co., 1992.

Loewe, Michael (ed.). Early Chinese Texts: A Bibliographical Guide. Berkeley: Institute of East Asian Studies, 1994.

Palme, Martin. The Book of Chuang Tzu: A New Complete Translation of the Classic Taoist Text. Arkana: Penguin Books, 1996.

Weber, Max. The Religion of China: Confucianism and Taoism. New York: Macmillan, 1964.

Schwarz, Benjamin. World of Thought in Ancient China. Cambridge: Harvard University Press, 1985.

Thomasine, Kushner. "Yang Chu: Ethical Egoist in Ancient China." Western Discussion of Chinese Philosophy, Journal of Chinese Philosophy 7 (1980). p. 319-25.

Zhao, Yanxia. Father and Son in Confucianism and Christianity: A Comparative Study of Xunzi and Paul. Brighton/Portland: Sussex Academic, 2007. 